\title{
Anaemia in Children: Apathy in Healthcare Priorities
}

\author{
Tahir Shamsi* Asma Danish \\ National Institute of Blood Disease \& Bone Marrow Transplantation, Karachi, Pakistan.
}

A nutritional deficiency in younger age group includes both micro and macronutrient deficiencies leading to protein calorie malnutrition, failure to thrive, compromised immune function and nutritional anemia. Deficiencies of iron, vitamin $\mathrm{B} 12$, folic acid, and pyridoxine, compromise red cell production. Iron deficiency is the most common cause of nutritional anemia's worldwide [1]. Iron deficiency anemia (IDA) due to poor nutrition is commonly found during periods of active growth spurts i.e. infancy and adolescent age group. Chronic blood loss due to worm infestation and giardiasis contributes to iron deficiency. Inflammatory bowel disease and coeliac disease are also associated with iron deficiency anemia [2]. According to a World Health Organization survey, $40-50 \%$ of preschool children \& $69 \%$ of children $<2$ years were iron deficient in Pakistani population [3]. Women of child bearing age who are iron deficient further replenish their iron stores after getting pregnant and this is a major preventable cause of perinatal morbidities worldwide [4]. A significant number of studies have shown a major correlation between maternal iron stores and its effect on iron status of the developing fetus, resulting in development of severe IDA during early infancy [4]. Furthermore, anemic pregnant women are susceptible to IUGR and preterm delivery of their child. Premature neonates are at increased risk for developing iron deficiency during the first 6 months of their life unlike term neonates, degree of deficiency being directly proportional to their level of prematurity and birth weight [4]. A number of factors predispose a premature infant to iron deficiency. Maternal iron deficiency, IUGR, and chronic blood loss during gestation and afterwards due to iatrogenic causes of increased phlebotomies further aggravate this deficiency. Premature infant's catch up growth is fast, this fact coinciding with onset of erythropoiesis further aggravates anemia during the first 6 months of life [4].

Food fortification, provision of food in schools, using boiled water for drinking, improvement in socioeconomic condition of the society and mother's education are some of the factors to prevent nutritional anemia.

As soon as iron deficiency is suspected, elemental iron at a dose of $3-6 \mathrm{mg} / \mathrm{kg} /$ day in divided doses should be started. Poor compliance to oral iron preparation is one the major cause of failure to respond to iron therapy (Ferrous Sulphate and Ferric

*Address correspondence to this author at the National Institute of Blood Disease \& Bone Marrow Transplantation, Karachi, Pakistan.

E-mail: t.shamsi.62@gmail.com compounds are notorious to cause gastric irritation) [5]. Iron polymaltose complexes are better absorbed without major gastrointestinal toxicity [6]. It should be continued for 3-6 months to correct anemia and to replenish iron stores. WHO IMNCI recommends deworming all anemic children above one year of age. A small subgroup of children may remain iron deficient due to malabsorption and non-compliance. $\beta$-Thalassemia is the most common genetic disorder in Pakistan and association of $\beta$-Thalassemia minor with iron deficiency anemia is commonly seen. $\mathrm{Hb}-\mathrm{A} 2$ production is dependent on the availability of iron; its absence or deficiency reduces its level and diagnosis of $\beta$-Thalassemia minor is masked [7]. Parenteral iron therapy, usually not considered in children, but its safety and efficacy has been shown in published data [8].

Folic acid, and less commonly, vitamin B12 deficiency present as megaloblastic anemia affecting children in developing countries [9]. Poor dietary intake, malabsorption due to giardiasis, coeliac disease, and inflammatory bowel diseases are common causes of folic acid deficiency [10]. Less commonly, anticonvulsant drugs and antimetabolites may lead to folic acid deficiency [11]. Goat milk is a poor source of folic acid; children raised on goat's milk develop folic aciddeficiency [12]. Vitamin B12 deficiency is caused by malabsorption disorders like Crohn's disease, chronic pancreatitis, and bacterial overgrowth of the small intestine, worm infestation, and surgical resection of terminal ileum. In children, juvenile pernicious anemia can also develop and leads to B12 deficiency [13]. In children with nutritional anaemia, microcytic hypochromic picture may predominate but many cases may be found to be concomitantly vitamin B12 and/or folic acid deficient [14, 15].

Pancytopenia may be a manifestation of severe prolonged vitamin B12 and/or folicdeficiency. $15-25 \%$ of the bone marrow examinations performed in patients presenting with pancytopenia are diagnosed as megaloblastic anemia $[16,17]$. In children presenting with pancytopenia and low reticulocyte count, vitamin B12 and serum and red cell folic acid levels should be checked and a trial of parenteral B12 and oral folic acid should be given. Treatment consists of IV Injection hydrocobalamine 500-1000 microgram IM/IV daily for 7 days. This is followed by weekly B12 for 1 month \& then monthly for 12-24 months. Emphasis should be given to remove the cause of deviancies. Dietary counseling, treatment 
of malabsorption condition, and treatment of giardiasis should be done.

Celiac disease is a very important malabsorption syndrome o be recognized early in life. It may have a wide spectrum of systemic clinical manifestations on presentation. Diarrhea and steatorrhoea lead to micronutrient deficiencies, weight loss, and failure to thrive. Coeliac disease can also present with subtle symptoms without diarrhea [18]. Hematological manifestations in coeliac disease are due to poor absorption of iron, folic acid, and vitamin B12. It can also present with cytopenias, non-functioning spleen and intestinal lymphomas [19].

Iron deficiency is frequently reported (46\% of cases), more prevalent in adults than children [20]. The cause of iron deficiency in celiac disease is mainly due to impaired absorption of iron but occult blood loss from gastrointestinal (GI) tract also contributed. A quarter of all patients with celiac disease also have occult gastrointestinal bleeding [21]. Main pathology of villous atrophy affects jejunum; main site of absorption of folic acid is this part, therefore patients with celiac disease commonly develop folic acid deficiency [22].

In Pakistan, during last three decades, processed beetle nut (with the addition of different aphrodisiacs, chemicals and grounded glass which causes mucosal abrasions and instantaneous absorption) addiction has become an epidemic [23]. Children and young adults also indulge in it. This affects their diet and oral and gastrointestinal mucosal damage [24, 25]. One study reported that $40 \%$ of the adolescent and young adults of slums of Karachi use at least one product of chewable tobacco on a daily basis [26]. The earliest manifestation of it, is losses of appetite, leading to nutritional deficiencies of Iron, B12, folic acid \& B complex. Physical damage to epithelial lining of digestive mucosa and deficiencies of these micronutrients adversely contribute to poor health of oral and gastric mucosa. There is a loss of its enzymatic function and ultimately causing oral sub mucous fibrosis and dysphagia [26]. Another study reported that school going children of government and private schools have a high prevalence of betel-nut consumption; $40.8 \%$ of children eat areca nut on regular basis while $39 \%$ use it occasionally [27]. This addiction is also associated with an increase incidence of oral cancers $[28,29]$.

\section{CONFLICT OF INTEREST}

Declared none.

\section{ACKNOWLEDGEMENTS}

Declared none.

\section{REFERENCES}

[1] Wieringa FT, Berger J, Dijkhuizen MA. Nutritional anemia in developing countries. Silverberg D, Ed. Anemia. UK: InTech 2012; Available from: https://www.intechopen.com/- books/anemia/nutritional-anemia-in-developing-countries

[2] Miller JL. Iron deficiency anemia: A common and curable disease. Cold Spring Harb Perspect Med 2013; 3(7): 1-13. DOI: $10.1101 /$ cshperspect.a011866

[3] WHO. Worldwide Prevalence of Anemia 1993-2005. WHO Global Database On Anaemia. Atlanta: Centers for Disease Control and Prevention. 2008; Available from http://whqlibdoc.who.int/publications/2008/9789241596657_eng.pdf

[4] Ziaei S, Hatefnia E, Togeh GH. Iron status in newborns born to iron-deficient mothers. IJMS 2002; 28(2): 62-4.

[5] Will AM. Disorders of iron metabolism: Iron deficiency, iron overload and the Sideroblastic anemias In: Arceci RJ, Hann I M, Smith OP, Eds. Pediatric Hematology. UK: Blackwell 2006; p. 91. DOI: 10.1002/9780470987001.ch5

[6] Komolafe JO, Kuti O, Ijadunola KT, Ogunniyi SO. A comparative study between intramuscular iron dextran and oral ferrous sulphate in the treatment of iron deficiencyanaemia in pregnancy. J Obstet Gynaecol 2003; 23: 628-31.

DOI: $10.1080 / 01443610310001604394$

[7] Saha L, Pandhi P, Gopalan S, Malhotra S, Saha PK. Comparison of efficacy, tolerability and cost of iron polymaltose complex with ferrous sulphate in the treatment of iron deficiency anemia in pregnant women. Med Gen Med 2007; 9: 1.

[8] Harthoorn-Lasthuizen EJ, Lindemans J, Langenhuijsen MM. Influence of iron deficiency anemia on hemoglobin A2 levels: Possible consequences for $\beta$-thalassemia screening. Scand J Clin Lab Invest 1999; 59: 65-70.

DOI: $10.1080 / 00365519950186011$

[9] Clark SF. Iron deficiency anemia. Nutr Clin Pract 2008; 23(2): 128-41. DOI: $10.1177 / 0884533608314536$

[10] Auerbach M, Ballard H. Clinical use of intravenous iron: Administration, efficacy, and safety. Hematol Am Soc Hematol Educ Prog 2010; 2010: 338-47.

DOI: 10.1182/asheducation-2010.1.338

[11] Anbu AT, Kemp T, O'Donnell K, Smith PA, Bradbury MG. Low incidence of adverse events following 90-minute and 3 -minute infusions of intravenous iron sucrose in children on erythropoietin. Acta Paediatr 2005; 94(12): 1738-41. DOI: 10.1111/j.1651-2227.2005.tb01846.x

[12] Roganovic J, Brgodac E, Dordevic A. Parenteral iron therapy in children with iron deficiency anemia. Paediatr Today 2015; 11(1): 24-9. DOI: $10.5457 / \mathrm{p} 2005-114.106$

[13] Crary SE, Hall K, Buchanan GR. Intravenous iron sucrose for children with iron deficiency failing to respond to oral iron therapy. Pediatr Blood Cancer 2011; 56(4): 615-9.

DOI: $10.1002 /$ pbc. 22930

[14] Lerner NB. Megaloblastic anemia In: Behraman RE, Kleig- 
man RM, Arbin AM, Eds. Nelson Text Book of Peadiatrics. USA: Elsevier, WB Saunders Company 2011; pp. 1655-6.

[15] Kakepoto GN, Iqbal MP, Iqbal SP. Megaloblastic anaemia is a hospital-based population. Med Sci Res 2000; 28: 45-7.

[16] Hashim H, Tahir F. Frequency of vitamin B12 and folic acid deficiencies among patients of megaloblastic anaemia. Ann Pak Inst Med Sci 2006; 2(3): 192-4.

[17] Khan A, Aqeel M, Khan TA, Munir A. Pattern of hematological diseases in Hospitalized pediatric patients based on bone marrow examination. JPMI 2008; 22(3): 196-200.

[18] Bhatnagar S, Chandra J, Narain S, et al. Pancytopenia in children - Etiological profile. J Trop Pediatr 2005; 51: 296-9. DOI: $10.1093 /$ tropej/fmi010

[19] Green PH, Jabri B. Coeliac disease. Lancet 2003; 362: 383-91. DOI: $10.1016 / \mathrm{S} 0140-6736(03) 14027-5$

[20] Brousse N, Meijer JW. Malignant complications of coeliac disease. Best Pract Res Clin Gastroenterol 2005; 19: 401-12. DOI: 10.1016/j.bpg.2005.02.002

[21] Bottaro G, Cataldo F, Rotolo N, Spina M, Corazza GR. The clinical pattern of subclinical/silent celiac disease: An analysis on 1026 consecutive cases. Am J Gastroenterol 1999; 94: 691-6. DOI: 10.1016/S0002-9270(98)00819-3

[22] DeVizia B, Poggi V, Conenna R, Fiorillo A, Scipp L. Iron absorption and iron deficiency in infants and children with gastrointestinal diseases. J Pediatr Gastroenterol Nutr 1992; 14: 21-6. DOI: 10.1097/00005176-199201000-00005

[23] Haapalahti M, Kulmala P, Karttunen TJ, et al. Nutritional status in adolescents and young adults with screen-detected celiac disease. J Pediatr Gastroenterol Nutr 2005; 40: 566-70. DOI: 10.1097/01.MPG.0000154658.16618.F9

[24] Halfdanarson TR, Litzow MR, Murray JA. Hematologic manifestations of celiac disease. Blood 2007; 109(2): 412-21. DOI: 10.1182/blood-2006-07-031104

[25] Dickey W, Hughes DF. Histology of the terminal ileum in coeliac disease. Scand J Gastroenterol 2004; 39: 665-7. DOI: $10.1080 / 00365520410004901$

[26] Chaturvedi P. Gutka or areca nut chewer's syndrome. Indian J Cancer 2009; 46: 107-2. DOI: 10.4103/0019-509X.49158

[27] Rajendran R. Oral submucous fibrosis. J Oral Maxillofac Pathol 2003; 7: 1-4.

[28] Sarfaraz M, Ali A, Mirza T. Prevalence and characteristics of areca nut chewing habit among school going children in Karachi. J Dow Uni Health Sci 2014; 8(3): 111-16

[29] Khawaja MR, Mazahir S, Majeed A, et al. Knowledge, attitude and practices of a Karachi slum population regarding the role of products of betel, areca and smokeless tobacco in the etiology of head and neck cancers. J Pak Med Assoc 2005; S41[Abstract].

(C) 2018 National Journal of Health Sciences.

This is an open-access article. 